\title{
Partial Discharge Control In A Power Electronic Module Using High Permittivity Non-Linear Dielectrics
}

\author{
Ningyan Wang, lan Cotton \\ School of Electrical \& electronic Engineering \\ The University of Manchester \\ Ferranti/C3, Sackville Street, Manchester, M13 9PL,UK \\ and Jeff Robertson \\ M\&I Materials Ltd, Hibernia Way, \\ Trafford Park, Manchester M32 0ZD, UK \\ and Sarah Follmann \\ Siemens Energy, 2 Koppers Way \\ Monkton Business Park South, Hebburn \\ Tyne \& Wear, NE31 2EZ, UK
and Kim Evans, David Newcombe
Dynex Semiconductor \\ Doddington Road, Lincoln, LN6 3LF, UK
}

\begin{abstract}
High electric fields at the edge of the substrate metallisation can give rise to partial discharge within power electronic modules and can lead to eventual failure. This paper examines the use of silicone gels filled with barium titanate to reduce the electric field enhancement at the edge of substrate metallisation and therefore increase partial discharge inception voltages. The barium titanate filled gel produces a dielectric in which the relative permittivity is increased over a plain gel and that also exhibits a dependence on electric field. The theoretical electric field reduction that can be achieved in a power electronic module through the use of filled gels is demonstrated and compared against experimental measurements including the trial of the technique in some commercial modules. As promising results are achieved, consideration is also given to the effect of the barium titanate filler on the viscosity of the gel and the thermal conductivity, two key manufacturing issues.
\end{abstract}

Index Terms - Power electronics, Partial discharges, Silicone insulation,

Ferroelectric materials, Finite element methods.

\section{INTRODUCTION}

The increased desire to use power electronic modules at higher voltages in applications that demand reliable operation means that care must be taken in the design of the insulation system. Modules that operate at voltages over $5 \mathrm{kV}$ are available and there will always be a drive to improve the power density of the module by raising voltages or by miniaturization. To do this, weak points in the dielectric system must be progressively improved. A cross-section of a typical power electronic module is given in Figure 1.

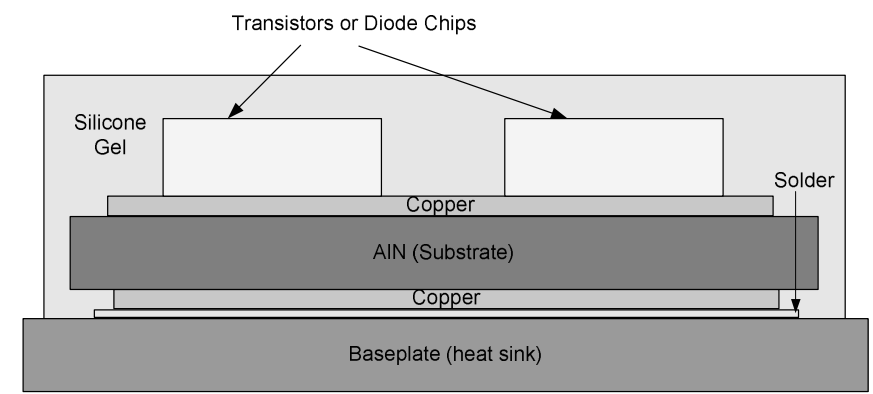

Figure 1. Cross-section view of typical power modules

Key to the module is the metallised substrate that is soldered onto a baseplate. Different techniques can be used to achieve this such as directly bonded copper or active metal brazing. The substrate used in high voltage modules 
is usually made from aluminum nitride (AlN) or aluminium oxide ceramic (the former being preferred at high voltages) with a good dielectric strength and a good thermal conductivity. The high voltage silicon IGBTs / diodes are soldered onto the substrate metallisation. Wire bonds are used to make connections between the individual IGBT / diode terminals and external connections for gate drives / busbars. The whole assembly is immersed in a soft encapsulant, typically silicone gel, in order to provide the dielectric strength along the surfaces of the substrate, between the busbars and between any other parts of the module subject to high electric fields. An epoxy layer may then be added over the top of the entire dielectric system to implement extra protection from environmental factors such as moisture, dust and other contaminants as well as providing mechanical strength for the entire module.

There are therefore three main dielectric systems within a power electronic module. One is the ceramic substrate, typically made of aluminum nitride or aluminium oxide. The second is the silicone gel which is used as an encapsulant. This fills the entire module housing and prevents partial discharges or breakdowns developing within the module. The final dielectric system is formed at the interface of these two components and it is this that is often the weakest point in a power module.

Testing of the ceramic substrates is fairly straightforward as they can be tested when produced, before they are used in the power electronic module. The electrical stress seen by the substrate when it is in use is also well represented during standard qualification test procedures. Thought to cause failure of substrates is the presence of cracks within the microstructure of the material [1]. Partial discharge activity induced by these defects will ultimately limit the module lifetime as the dielectric integrity of the substrate is compromised.

The silicone gel used in the manufacture of power electronic modules is more difficult to produce and test. When pouring gels, it is essential to ensure the absence of air bubbles in the module as these would otherwise form locations in which partial discharge could arise. This is typically done by degassing the gels using a vacuum but this technique is not foolproof. Modules are tested according to IEC standard 61287 to discover any possible defects caused during the manufacturing process. However, there may be untested areas of silicone gels when the module leaves the factory owing to the inability of the standard module test method to stress all parts of the silicone gel encapsulation [2]. This is due to the test being carried out with all terminals being bonded to high voltage while in operation they can, depending on the exact nature of the switch position, be at different potentials [3]. Silicone gel should not age under the presence of an electric field alone [4] but may vary in performance according to the environmental conditions. For example, ambient temperature is known to have a significant impact on the dielectric performance of materials such as silicone gel [5, $6]$. This is mainly due to the condensation of water out of the gel at lower temperatures, a process that significantly limits the dielectric performance of a gel [7]. Cracks were observed in the gel embedding the ceramic substrate after 24 hours exposure to $-60^{\circ} \mathrm{C}$ [5]. As a result, the partial discharge inception voltage was significantly reduced due to the field enhancement caused by these cracks in proximity to the edge of the substrates.

Even though there can be quality issues with the substrate and gel materials as described above, the critical area in which the insulation system of a power module appears to limit the ultimate performance is at the edge of the metallisation of the substrate [8]. The performance of silicone gel is particularly critical in this location not just in terms of preventing discharge within the gel itself but also in terms of preventing discharge at the gel-substrate interface in close proximity to the metallisation. Some researchers have investigated the use of semi-conductive coatings in this area to relieve the dielectric stress [9]. In other work, the same authors reinforce the belief that partial discharges from metallised edges of substrates and silicone gel interfaces are the main sources of partial discharge in a power module [10]. Electrical field simulation results show that maximum field is around the edge of the substrate metallisation and this has been verified by optical detection [8]. Improvement of the partial discharge / breakdown behavior in this area of the module is therefore the topic of this paper.

\section{High Permittivity / Non-Linear DiELECTRICS}

In all applications and irrespective of the type of stress relieving dielectric to be used, the aim would be to reduce the peak electrical stresses seen in insulation, particularly around defects, with a view to minimising partial discharge activity and prolonging the time to failure of the insulation system.

Two forms of stress relieving composite dielectrics exist; a form that varies the conductivity of a material with the electric field (field dependent conductivity - FDC) and a form that varies the permittivity of a material with the electric field (field dependent permittivity - FDP) [11].

FDC stress relieving dielectrics are formed through the inclusion of narrow band semi-conductive fillers, such as zinc oxide or silicon carbide, in the base polymer / gel. Their functionality as a stress relieving material relies on their ability to allow charge to flow through the dielectric at elevated field strengths. The non-linear nature of these composites is a function of the intrinsic semi-conductive nature of the particles themselves and also as a function of particle connectivity. In order for the stress relieving nature to occur, the filler concentration must be above a prescribed limit (known as the percolation threshold) to allow particle to particle contact. The electrical field strength must also be great enough to allow conduction through the semiconductive particles and through barriers between particles 
$[12,13]$. As the production of a field dependent conductive dielectric requires particle to particle contact (and hence high filler rates), this option was not pursued in this work since the effect on the non-electrical properties of the silicone gel would be significant (particularly in terms of viscosity / flow).

FDP stress relieving dielectrics are formed through the inclusion of ferroelectric fillers, such as barium titanate or lead zirconium titanate (PZT), in the base polymer / gel. Their functionality as a stress relieving material relies on enhanced polarization mechanisms (through a process of spontaneous domain alignment) occurring in the ferroelectric filler particles at elevated electrical field strengths. These enhanced polarization effects then give the composite dielectric an enhanced permittivity at elevated electrical field strengths. These processes do not require a percolation criteria in order to operate and occur even at low electrical field strengths. Such spontaneous domain alignment disappears above a certain temperature which is termed the Curie point. For pure barium titanate, the Curie temperature is approximately $130^{\circ} \mathrm{C}$ [14]. In a filled gel, this Curie point increases and is at a level that is above the maximum junction temperature of IGBT devices of $150^{\circ} \mathrm{C}$ in the transistor and $125^{\circ} \mathrm{C}$ in the diodes [15]. However, as the stress relieving properties of the material are driven through electrical field dependent polarization / permittivity mechanisms, the effects are only realizable under $\mathrm{AC}$ fields.[16-19]

Other benefits not related to the control of the electric field may also result from the use of filler materials. A good example of this is the thermal conductivity of the filler material, a property that if increased benefits (albeit weakly) the power electronic modules. Filler particles have higher thermal conductivities than polymers or gels. It has been shown in [20] that an increase in the thermal conductivity of silicone composites occurs when fillers are used. The value moves from $1 \mathrm{~W} / \mathrm{mK}$ with $10 \%$ of aluminium trihydrate filler to a value of $6 \mathrm{~W} / \mathrm{mK}$ for a $50 \%$ filler concentration (the filler itself having a thermal conductivity of $21 \mathrm{~W} / \mathrm{mK}$ ). It has also been shown in [11] that inclusion of both zinc oxide and barium titanate can improve the thermal conductivity of the stress relieving composites.

The inclusion of these stress relieving dielectrics into power electronic modules may therefore have the ability to reduce high electrical stresses that are formed by either poor manufacturing or errors in design. This would help to reduce the partial discharge related failure rates that can currently occur on low volume production runs of high value power electronic modules. It would also significantly improve the reliability of power electronic modules as insulation defects that did not show up in initial testing but which exist and have the ability to cause cumulative damage would be reduced in severity by the non-linear dielectric characteristics.

In this work, barium titanate was chosen as the filler material. The inclusion of barium titanate into the silicone gel does not significantly disturb the curing characteristics of the gel and nor does it significantly affect the adhesive qualities. In comparison to other materials such as lead zirconium titanate, the use of barium titanate also produces a filled gel that (in the UK) can be disposed off without special precautions.

\section{Characterization Of Filled Silicone GEL}

Before a filled gel could be placed in a module and in order to model the effect of a field dependent permittivity material on the peak electric field around the substrate edge, it was necessary to characterize the material. The test samples used for this purpose had a $1 \mathrm{~mm}$ thickness of insulation placed between two $20 \mathrm{~mm}$ diameter plane electrodes (guard electrodes were also present in the test cell). The test system used to measure the permittivity as a function of electric field comprised a high voltage AC amplifier with a peak output voltage of $20 \mathrm{kV}$ which was controlled by a signal generator. The combination of signal generator and amplifier was used instead of a transformer to ensure a pure sine-wave without any harmonic disturbances in the signal. These would have invariably been present if the mains voltage had been stepped up through a transformer. This is essential in this experiment so as to ensure distortions seen during test are caused by the nonlinearity of the test sample instead of the transformer. All the tests reported in this work were done at $50 \mathrm{~Hz}$.

Mounted in series with the test object was a resistor used to measure the current passing through the sample. The voltage and the current passing through the sample was recorded simultaneously and was converted to equivalent electrical field $\mathrm{E}(\mathrm{kV} / \mathrm{mm})$ and current densities $\mathrm{J}$ (A / $\mathrm{mm}^{2}$ ) thus making the measurement result independent of sample geometry. Three samples each of unfilled gel and of a filled gel containing $15 \%$ by volume of barium titanate were produced and tested.

Figure 2 shows the traces of voltage and current for one plain silicone gel sample converted to field strengths (light grey line) and current densities (dark grey line). Multiple voltage and current traces are reported in the same figure. The waveforms of all current traces are purely sinusoidal without any distortions. The current is $90^{\circ}$ lagging, the test sample being capacitive. For the peak electrical field strength of $18.4 \mathrm{kV} / \mathrm{mm}$, the peak current density is about $0.14 \mathrm{~A} / \mathrm{m}^{2}$. This equates to a sample capacitance of around $30 \mathrm{pF}$. 


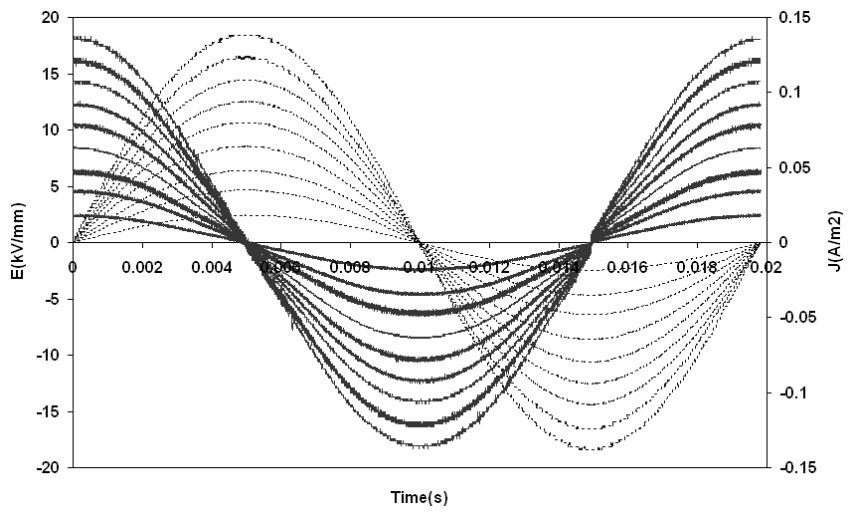

Figure 2. Current density and electrical field strength measured for a plain silicone gel sample

Figure 3 depicts the waveforms measured for the $15 \%$ barium titanate filled sample. This sample was prepared in a similar way to a normal gel but $15 \%$ by volume of barium titanate was thoroughly mixed into one part of the gel before the second gel component was introduced. Full details of this process are given in section IV of the paper. In this case, the current waveform has a different shape compared to the plain sample. The phase shift is now less than $90^{\circ}$ owing to an increase in the dielectric loss angle and significant harmonic distortion is present. This harmonic distortion can be explained by the influence of the barium titanate filler and shows that the compound is affected by the properties of the filler due to ferroelectric domain alignment processes. The harmonic distortion increases as the field strength is increased.

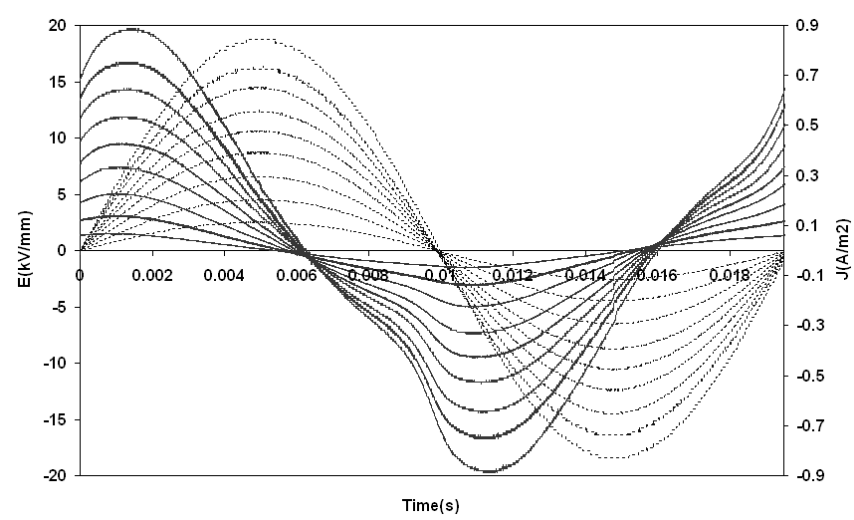

Figure 3. Current density and electrical field strength measured for a $15 \%$ (by volume) barium titanate filled silicone gel sample

To show whether the magnitudes of the electric field and current density within the sample are non-linear, the peak current density and the peak electric field strength are plotted in Figure 4. A fit to the measured values is also shown which can be represented by equation 1 .

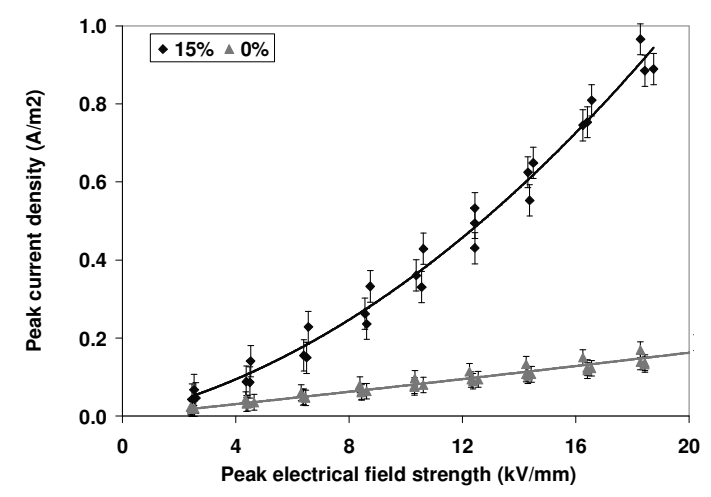

Figure 4. Peak current density against peak electrical field strength in a filled silicone gel sample

$$
J=\left[0.0164 E+0.0018 E^{2}\right] A / m^{2}(1)
$$

A linear dielectric, i.e. one in which the capacitance did not vary as a function of electric field, would not be expected to contain a term relating to the square of the electric field. This therefore confirms that non linear behaviour is taking place. The relative permittivity of the gel as it moves through different levels of electric field can be calculated using the points ' $n$ ' and ' $n+1$ ' on the trend line as shown in equation 2. Relative permittivity values derived from this method has been termed the 'static permittivity value' in [16]. As it is derived from the gradient of the curve along the $\mathrm{J}(\mathrm{E})$ characteristic, this value best describes how the electrical characteristics of the dielectric change as the electrical field in an application changes. This is therefore the most appropriate value to use in the finite element analysis of stress relieving applications, as in the power electronics module.

$$
\varepsilon_{\mathrm{rn}}=\frac{\Delta J}{2 \pi f \varepsilon_{0} \Delta E}=\frac{J_{n+1}-J_{n}}{2 \pi f \varepsilon_{0}\left(E_{n+1}-E_{n}\right)}
$$

For the sample filled with $15 \%$ barium titanate, the permittivity was shown to take the form given in equation 3 . The unfilled silicone gel was shown to have a relative permittivity of 2.7 and this was not dependent on the electric field (i.e. the second order term seen in equation 3 was not significant for this set of measurements). Figure 5 shows the relative permittivity values of filled gels at various concentrations.

$$
\varepsilon_{\mathrm{r}}(\mathrm{E})=6.4+1.3 E
$$




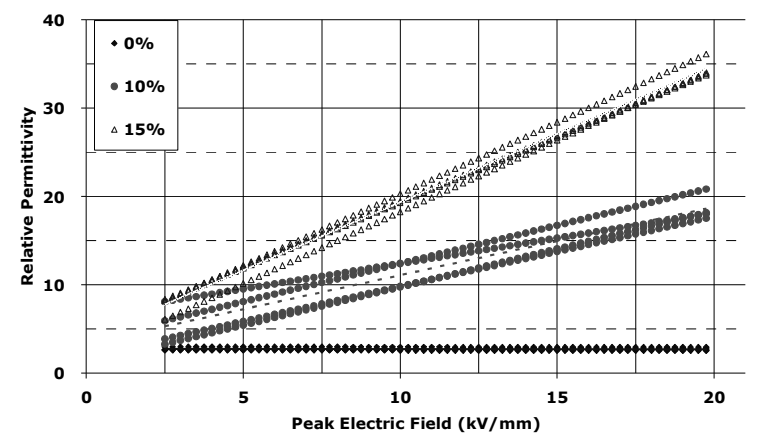

Figure 5. Relative permittivity of filled gel at various concentrations at $50 \mathrm{~Hz}$ for a number of samples

It is important to note, as previously discussed, that the field dependent aspect of the permittivity will only manifest itself when the filled gel is subject to an alternating field. Under a DC field, this behavior will not be apparent and as such any benefit in terms of the use of filled gels will only be a result of the increased permittivity that they exhibit.

\section{Electrostatic Finite Element Analysis STUDIES}

Electrical simulations for determining the electrical field distribution inside a power electronics module are commonly used to help to identify locations where the electric field strength is particularly high. These simulations can be used for layout optimization and deliver quantitative results. The simulations can represent the power electronic module in its entirety and therefore usually model the substrate with its copper metallisation, the base plate and the soft silicone that encapsulates the whole module. Such simulations can be of great use in reducing the product development cost.

A power electronic module does present a number of challenges when it is modeled, these mainly being a result of the relatively thin size of some of the insulation layers in comparison to the length / width of the module. The software used to produce the electric field distributions discussed in this paper was OPERA 3D. It is a general purpose electromagnetic analysis software but has the ability to model permittivity as a function of electric field. Using this facility, the relationship between electric field and permittivity given as equation 3 can be implemented within the software.

A model of a $3.3 \mathrm{kV}$ four switch power electronic module has been created in Opera 3D. It consists of four AIN substrates lying in a symmetric configuration. For best simulation accuracy, only a quarter of the whole module, namely one substrate has been focused on in this study. By altering the boundary conditions within the model, the electric fields within the module can be investigated when the switches are in a number of configurations. The effect of transient voltage overshoots can also be included in the simulations by making adjustments to the magnitudes of the voltages imposed on sections of the substrate metallisation. The substrate edges have been rounded at $0.1 \mathrm{~mm}$ radium in the simulation.

Figure 6 illustrates the electrical field distribution on the substrate surface in the test configuration used in the experimental measurements of the filled gel performance. In the test, the collector of the substrate metallisation is connected to high voltage while the emitter is connected to earth. This provides a more realistic test than is used once substrates are populated with silicone as the collector emitter gap is stressed as well as the outer edge of the metallisation. The field distribution is indicated by the color shading. In the figure, it can be directly seen that the electrical field strength reaches its peak at the edge of substrate metallisation. In consequence, partial discharges will most likely start at this location. This result clearly matches that of other researchers as discussed in the introduction section.

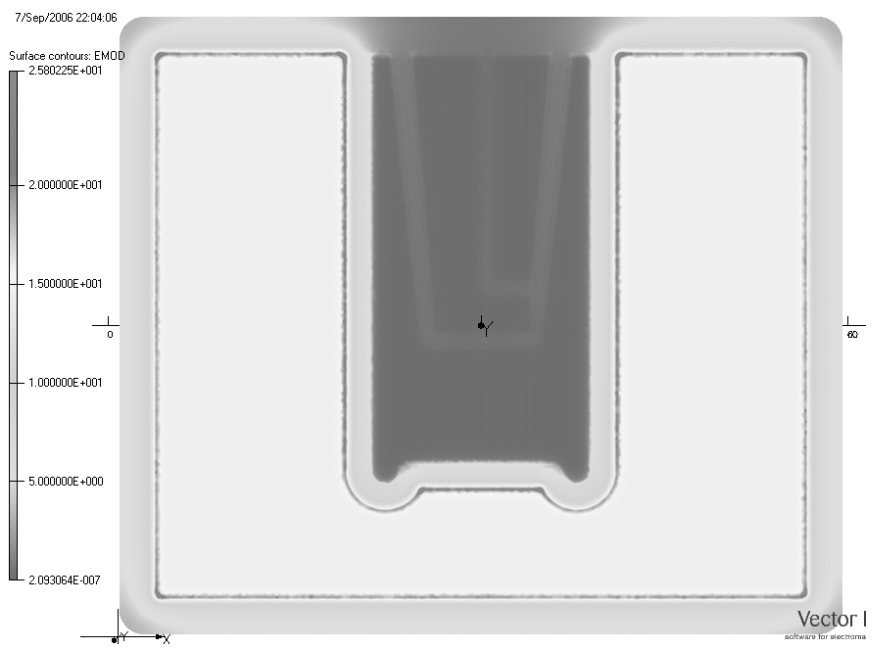

Figure 6. Electrical field distribution on one substrate surface

This model was used to produce a relationship between the maximum field strength observed on the edge of the substrate metallisation and the applied voltage for three different types of gel. A standard silicone gel was modeled as was a filled gel with and without non-linear properties. The plain silicone gel had a permittivity of 2.7 while the filled gel had a permittivity of 6.4. Non-linear behavior was accounted for by means of the use of equation 3 within the software.

It is obvious from the results in figure 7 that for the same voltage level, the systems containing pure gel will reach the highest field strength followed by the filled gel with fixed permittivity and ultimately the filled gel when non-linearity is also accounted for. The enhanced permittivity of the filled gel reduces the peak electric field within the module by around $10 \%$. However, when the non-linear performance of the filler is accounted for, the reduction is increased to $24 \%$ at $6 \mathrm{kV}$ and $29 \%$ at $12 \mathrm{kV}$ as shown in Table 1. 


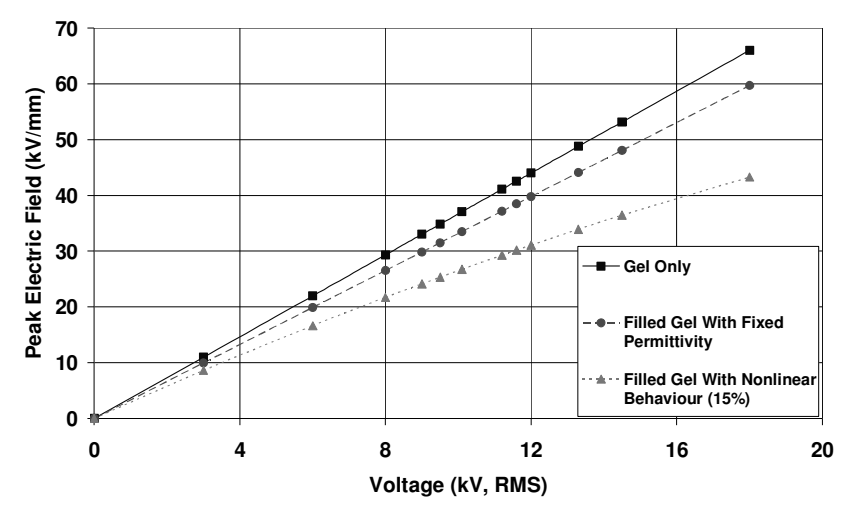

Figure 7. Maximum field strength versus applied voltage for three different conditions

Table 1. Maximum field observed in the model for different gel types (values in brackets represent magnitude of peak field compared with unfilled gel)

\begin{tabular}{|c|c|c|c|}
\hline $\begin{array}{c}\text { Applied } \\
\text { Voltage (RMS) }\end{array}$ & $\begin{array}{c}\text { Gel Only } \\
(\mathbf{k V} / \mathbf{m m})\end{array}$ & $\begin{array}{c}\text { Filled Gel (Fixed } \\
\text { Permittivity) } \\
(\mathbf{k V / m m})\end{array}$ & $\begin{array}{c}\text { Filled Gel } \\
\text { (Non-Linear) }\end{array}$ \\
\hline $6 \mathrm{kV}$ & 22 & $19.9(90 \%)$ & $16.7(76 \%)$ \\
\hline $12 \mathrm{kV}$ & 44 & $39.8(90 \%)$ & $31.1(71 \%)$ \\
\hline
\end{tabular}

\section{Experimental Testing Of Substrate- GeL SAMPLES}

Given the promising results from the modeling, actual samples were produced and tested within the laboratory. The samples tested consisted of a metallised aluminum nitride substrate. Two metallic connections were soldered onto the collector and the emitter. These were used to connect wires for eventual connection to the $\mathrm{HV}$ test equipment. The collector was connected to the high voltage electrode while the emitter and all the small metallisation components within were connected to earth. This is a similar test arrangement to that used by other researchers $[5$, $10,21]$ with the exception of the way the collector and emitter are connected.

Following inspection of the samples to ensure that they are clean, they are placed in a container whose sides are a sufficient distance from the edge of the metallisation so as not to influence the electric field. For samples using unfilled gel, silicone gel is then poured into the container to encapsulate the substrate. Once the silicone gel has been poured, the samples are degassed under a vacuum for a period of 15 minutes before being cured in an oven at a temperature of $90^{\circ} \mathrm{C}$ for one hour. The filled samples are made in the same way but $15 \%$ by volume of barium titanate was introduced into part $\mathrm{A}$ of the silicone gel and thoroughly mixed before addition of part B. The same vacuum and cure process was used on these samples. The final test piece is as shown in Figure 8.

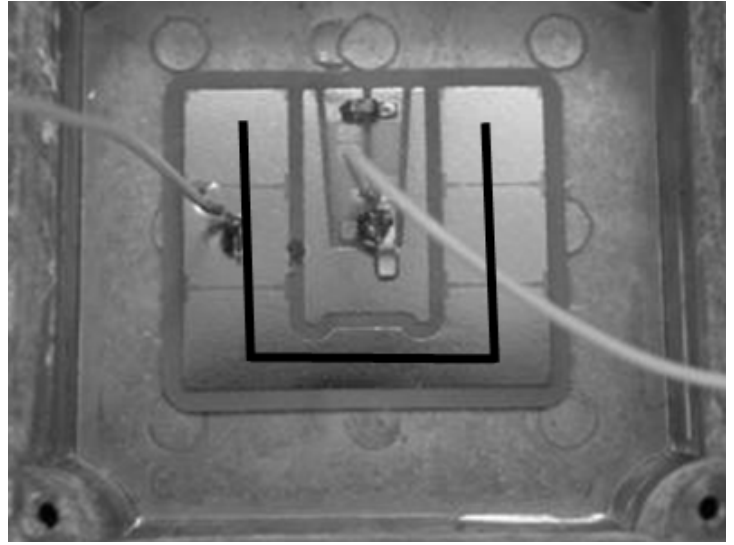

Figure 8. Substrate embedded in gel as used in the partial discharge and breakdown tests

A set of 60 samples including 30 unfilled and 30 filled with $15 \%$ barium titanate by volume were made and then placed in an environmental chamber. These samples were thermally cycled in an environment with an average relative humidity of $25 \%$. The thermal cycling took the temperature from $20^{\circ} \mathrm{C}$ to $90^{\circ} \mathrm{C}$ and back, the temperature being changed over a 20 minute period with the temperature being held at each level for 20 minutes.

When the samples were tested, they were placed in a darkened enclosure in which a night-vision camera was placed. This allowed visible records of discharge location to be collected (in the case of the unfilled samples only - the filled samples not being translucent). A transformer, fed from a variable voltage mains supply, was used to energise the samples. A conventional partial discharge measurement circuit according to IEC 60270 was used to measure the discharge inception voltage and partial discharge distribution. A typical image captured from the night vision camera during the tests is shown in Figure 9. Discharge can be seen in this example both at the edge of the metallisation on the outer edge of the collector as well as within the collector-emitter gap. It is this latter form of discharge that would not have been observed by other researchers.

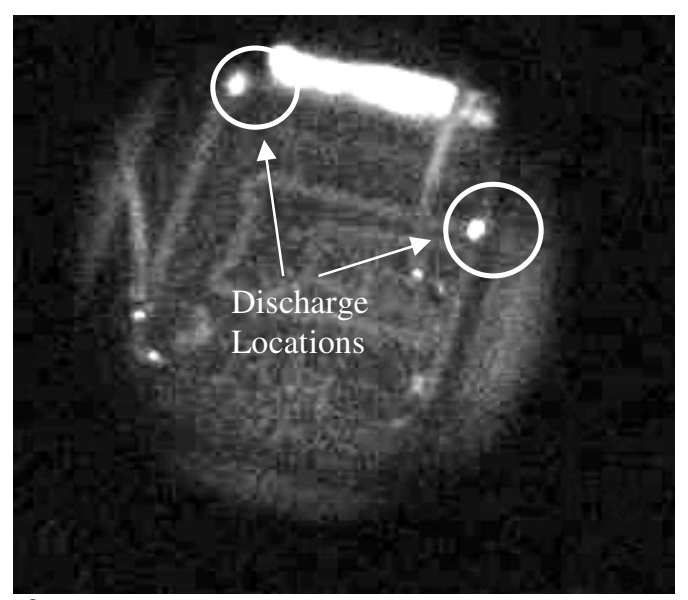

Figure 9. A typical image as recorded by the night vision camera 
When testing the samples, the $50 \mathrm{~Hz}$ supply voltage was raised at $500 \mathrm{~V} / \mathrm{s}$ until the inception voltage was measured. After collecting 60 s of partial discharge data, the voltage was further increased until a breakdown of the sample occurred. The results of these tests for 30 samples in each case are plotted in Figure 10. This shows the cumulative probability of reaching the partial discharge inception voltage.

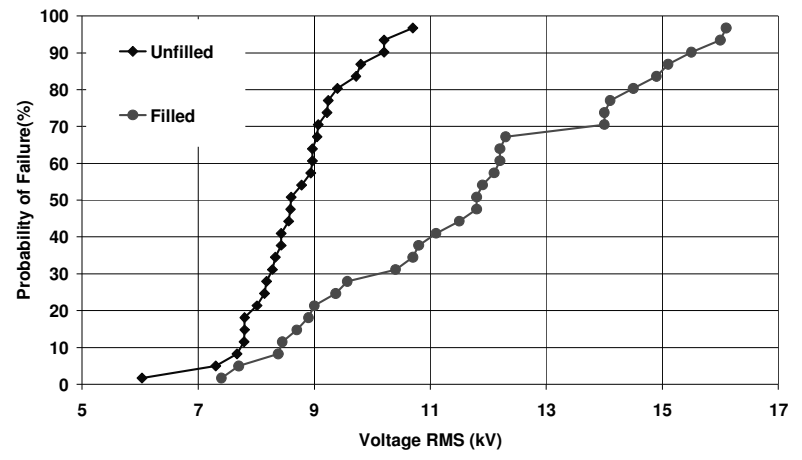

Figure 10. Probability of failure in partial discharge in both filled and unfilled samples

The filled gel shows a clear improvement in terms of the PD inception voltage in comparison with unfilled modules. The improvement in performance is not linear over the probability range. This is to be expected since at higher voltages, the non-linear nature of the filled gel provides an ever increasing performance advantage in comparison to the unfilled gel. Table 2 summarises a number of partial discharge inception voltages corresponding to the $10^{\text {th }}, 50^{\text {th }}$ and $90^{\text {th }}$ percentile.

Table 2. Probability of failure at different voltage level in both filled and unfilled gel

\begin{tabular}{|c|c|c|c|}
\hline Percentile & $\begin{array}{c}\text { Voltage for unfilled } \\
\text { samples / kV }\end{array}$ & $\begin{array}{c}\text { Voltage for filled } \\
\text { samples / } \mathbf{~ V}\end{array}$ & $\begin{array}{c}\text { \%age } \\
\text { increase }\end{array}$ \\
\hline $10 \%$ & 7.7 & 8.4 & 9.1 \\
\hline $50 \%$ & 8.6 & 11.8 & 37.2 \\
\hline $90 \%$ & 10 & 15.3 & 53.0 \\
\hline
\end{tabular}

Examining the FEA results at these voltages allows us to examine the values of peak field seen at the substrate-gel interface when partial discharge occurred. These values are given in the table below:

Table 3. Peak field at substrate-gel interface when discharge occurred in filled and unfilled samples

\begin{tabular}{|c|c|c|}
\hline $\begin{array}{c}\text { Prob. of } \\
\text { failure }\end{array}$ & $\begin{array}{c}\text { Peak Field for } \\
\text { unfilled samples } \\
(\mathbf{k V / m m})\end{array}$ & $\begin{array}{c}\text { Peak Field for filled } \\
\text { samples } \\
\mathbf{( k V / m m})\end{array}$ \\
\hline $10 \%$ & 28.3 & 22.7 \\
\hline $50 \%$ & 31.5 & 30.6 \\
\hline $90 \%$ & 36.7 & 38.1 \\
\hline
\end{tabular}

The data in this seems to suggest that failures will happen at similar levels of electric field in both sets of sample (the filled gel means though that this level of field happens at a higher voltage). At the $50^{\text {th }}$ percentile of partial discharge, the peak field in unfilled is $31.5 \mathrm{kV} / \mathrm{mm}$ while for the filled gel it appears to be $30.6 \mathrm{kV} / \mathrm{mm}$. This result once again confirms that the non linear property of filled gel will reduce the peak field in the sample and therefore improve the performance at higher voltage.

\section{Experimental Testing Of Actual IGBT MODULES}

In addition to the tests detailed, a number of actual IGBT modules have been tested. These modules are intended to operate at $3.3 \mathrm{kV}$ and have been sourced directly from a manufacturing production line. Twelve samples were tested in total using the method given in IEC 61287 [2]. Six of the test samples used an unfilled gel while the other six used a filled gel containing $15 \%$ by volume of barium titanate. The results of the partial discharge tests are as shown in Table 4. Whether looking at the maximum, mean or minimum partial discharge inception voltage of the samples, a $60 \%$ improvement is always seen. This vastly exceeds the improvement seen for the simpler test samples but may be related to the slightly different test configuration that has to be employed for samples populated with devices and the better conditions that exist in the manufacturing environment for the production of test objects.

Table 4. Partial discharge inception voltages of actual $3.3 \mathrm{kV}$ modules with filled and unfilled gel

\begin{tabular}{|l|l|l|l|}
\hline & $\begin{array}{l}\text { Unfilled Gel / } \\
\mathrm{kV}\end{array}$ & Filled Gel / kV & $\begin{array}{l}\text { \%age } \\
\text { increase }\end{array}$ \\
\hline Maximum & 8.0 & 13.4 & 67.5 \\
\hline Mean & 6.3 & 10.1 & 60.3 \\
\hline Minimum & 4.8 & 7.8 & 62.5 \\
\hline
\end{tabular}

\section{MANUFACTURING ISSUES}

While the use of filled gels has been shown beneficial from the perspective of partial discharge control, it is important that they are still able to provide manufacturers with physical properties that do not differ significantly from those of the unfilled gels. To verify the potential impact of fillers on the physical properties of the gels, the thermal conductivity, density and viscosity of unfilled and filled samples have been either measured or calculated.

In terms of density, the silicone gel used in this set of trials has a density of $0.96 \mathrm{~g} / \mathrm{cc}$ when set. Barium titanate has a density of $5.95 \mathrm{~g} / \mathrm{cc}$. When $15 \%$ by volume of barium titanate is added to the gel, the density will rise to $1.7 \mathrm{~g} / \mathrm{cc}$, an increase of $77 \%$ over unfilled gel. As the silicone gel used in a $3.3 \mathrm{kV}$ module typically constitutes around $14 \%$ of the total weight, this implies that the use of a filled gel will add around $11 \%$ to the total weight of a module.

Using a Brookfield viscometer, the viscosity of the unfilled and filled gels was measured just after mixing the two-parts of the raw material (the barium titanate was added to part $\mathrm{A}$ of the gel before part $\mathrm{B}$ was added). The viscosity of the filled gel was increased by around 5 times at $15 \%$ by volume. Although this is a significant increase, the filled 
composite was still capable of being poured into the module and it flowed well through the module, being evenly distributed once a vacuum had been applied.

In general, dielectric materials should be low loss to avoid concerns relating to thermal breakdown. The inclusion of barium titanate gives rise to an 18 times power loss of the silicone gel (15W in unfilled compared to $279 \mathrm{~W}$ in filled at $3 \mathrm{kV}$ peak voltage). However, as the heat generation in power electronic modules of the type tested in this work can be in the order of $9.6 \mathrm{~kW}$ in transistors, such an increase in loss tangent is not of significant concern.

The thermal conductivity of both filled and unfilled gel was measured. As expected, the inclusion of the filler in the gel improved the thermal conductivity from $0.161 \mathrm{~K} / \mathrm{mW}$ to $0.22 \mathrm{~K} / \mathrm{mW}$. The gel would not normally constitute a path in a module through which significant heat flows would take place but an increase in thermal conductivity would help eliminate hot spots located around the substrate / gel interfaces.

\section{Conclusions}

Silicone gels filled with $15 \%$ barium titanate by volume have been tested using $50 \mathrm{~Hz}$ voltages to measure their permittivity over a range of electric fields. They are shown to exhibit a non-linear behaviour in which the permittivity increases as a function of the applied electric field.

Finite element simulations demonstrate that the use of such gels in power electronic modules could significantly reduce electric field levels around the edges of the substrate metallisation, a location often considered to be the weak point of power electronic modules.

Experimental measurements of partial discharge inception voltages and breakdown voltages were taken using samples in which the peak fields occurred at the edge of substrate metallisation. The use of barium titanate filled gels was shown to significantly increase partial discharge inception and breakdown voltages when the samples were energised with $50 \mathrm{~Hz}$.

No significant manufacturing challenges are foreseen to exist if filled gels are implemented. A slight weight increase will take place but this is not significant considering the increase in voltage capability that would occur, i.e. the use of filled gels would allow an increase in power density. Although the viscosity of the filled gel is higher than the unfilled, given that it is still applicable and the advantage it offers, this is considerable promising.

\section{ACKNOWLEDGEMENTS}

The authors would like to acknowledge the financial support provided to this work by the IeMRC Flagship Project in Power Electronics (through the IeMRC Centre at Loughborough University) supported by EPSRC. They would also like to acknowledge the support of Dynex
Semiconductors Ltd.

\section{REFERENCES}

[1] D. Malec, S. Dinculescu, and T. Lebey, "Aging of ceramic materials used in power electronic substrates," presented at Electrical Insulation and Dielectric Phenomena, pp. 604-607 vol.602, 2000.

[2] IEC61287, "Railway applications -Power convertors installed on board rolling stock," 2005

[3] F. Breit, E. Dutarde, J. Saiz, T. Lebey, D. Malec, and S. Dinculescu, "Partial discharge detection in power modules," presented at Power Electronics Specialists Conference, IEEE 33rd Annual, pp. 748-752 vol.742, 2002.

[4] T. Ebke, A. Khaddour, and D. Peier, "Degradation of silicone gel by partial discharges due to different defects," presented at Eighth International Conference on Dielectric Materials, Measurements and Applications, pp. 202-207, 2000.

[5] T. A. T. Vu, J. L. Auge, and O. Lesaint, "Low temperature partial discharge properties of silicone gels used to encapsulate power semiconductors," presented at IEEE Conference on Electrical Insulation and Dielectric Phenomena, pp. 421-424, 2009.

[6] T. Do, O. Lesaint, and J. L. Auge, "Streamers and partial discharge mechanisms in silicone gel under impulse and AC voltages," IEEE Transactions on Dielectrics and Electrical Insulation vol. 15, pp. 1526-1534, 2008.

[7] G. Finis and A. Claudi, "Silicone gel as an insulation material for HV-insulation applications," presented at Proceedings of the XIVth International Symposium on High Voltage Engineering, Tsinghua University, Beijing, China, pp. I1-5, 2005.

[8] J. H. Fabian, S. Hartmann, and A. Hamidi, "Analysis of insulation failure modes in high power IGBT modules," presented at Industry Applications Conference, Fourtieth IAS Annual Meeting. Conference Record, pp. 799-805 Vol. 792, 2005.

[9] G. Mitic, T. Licht, and G. Lefranc, "IGBT module technology with high partial discharge resistance," presented at Industry Applications Conference, Thirty-Sixth IAS Annual Meeting, pp. 1899-1904 vol.1893, 2001.

[10] G. Mitic and G. Lefranc, "Localization of electrical-insulation and partial-discharge failures of IGBT modules," Industry Applications, IEEE Transactions on, vol. 38, pp. 175-180, 2002.

[11] B. R. Varlow, J. Robertson, and K. P. Donnelly, "Nonlinear fillers in electrical insulating materials," Science, Measurement \& Technology, IET, vol. 1, pp. 96-102, 2007.

[12] K. P. Donnelly and B. R. Varlow, "Nonlinear dc and ac conductivity in electrically insulating composites," Dielectrics and Electrical Insulation, IEEE Transactions, vol. 10, pp. 610-614, 2003.

[13] R. Strumpler and J. Glatz-Reichenbach, "Conducting Polymer Composites," Journal of Electroceramics, pp. 329-346, 1999.

[14] A.J.Moulson and

Electroceramics:Materials, Properties, A John Wiley \& Sons, 2003.

[15] "High Isolation Single Switch IGBT Module," Dynex Semiconductor 2005.

[16] J. Robertson and B. R. Varlow, "Non-linear ferroelectric composite dielectric materials," Dielectrics and Electrical Insulation, IEEE Transactions, vol. 12, pp. 779-790, 2005.

[17] B. R. Varlow and K. Li, "Non-linear AC properties of filled resins," Science, Measurement and Technology, IEE Proceedings, vol. 150, pp. 75-82, 2003.

[18] R. Strumpler, J. Rhyner, F. Greuter, and P. Kluge-Weiss, "Nonlinear dielectric composites," Smart Materials and Structures, pp. 215, 1995.

[19] D. A. Hall, "Rayleigh behaviour and the threshold field in ferroelectric ceramics," Ferroelectrics, vol. 223, pp. 319 - 328, 1999.

[20] E. A. Cherney, "Silicone rubber dielectrics modified by inorganic fillers for outdoor high voltage insulation applications," IEEE Transactions on Dielectrics and Electrical Insulation, vol. 12, pp. 1108-1115, 2005.

[21] M. T. Do, J. L. Auge, and O. Lesaint, "Optical measurement of partial discharges in silicone gel under repetitive pulse voltage," presented at International Symposium on Electrical Insulating Materials, pp. 360-363 Vol. 362, 2005. 


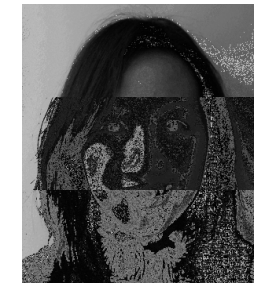

Ningyan Wang was born in China in 1981. She received a BSc in Electrical and Electronic Engineering from Shandong University in 2004 and an MSc in Electrical Power Engineering from the University of Manchester in 2005. She is currently a PhD student in the Electrical Energy and Power Systems Group of the School of Electrical and Electronic Engineering at the University of Manchester and is researching methods to improve the reliability of high voltage power electronic modules.

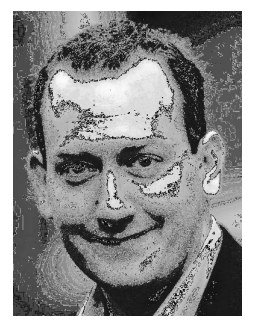

Ian Cotton (M'98, SM'05) was born in the UK in 1974. He received a Class I BEng (Hons) degree in Electrical Engineering from the University of Sheffield in 1995 and a PhD in Electrical Engineering from UMIST in 1998. He is currently a Senior Lecturer in the Electrical Energy and Power Systems Group of the School Of Electrical and Electronic Engineering at the University of Manchester. His current research interests include power systems transients, the use of higher voltage systems in aerospace applications and power system induced corrosion. He is a Member of the Institution of Electrical Engineers and a Chartered Engineer.

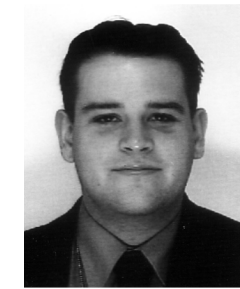

Jeff Robertson (M'02) was born in Liverpool, England. He completed both his BSc MEng degree in Electrical and Electronic Engineering and Eng D from the University of Manchester. After spending many years in both academic and industrial related research, studying the development and ageing of dielectric materials, he is currently working as the Technical Manager at company called M\&I Materials, based in Manchester. He is also an active committee Member of the IET in the Manchester Branch.

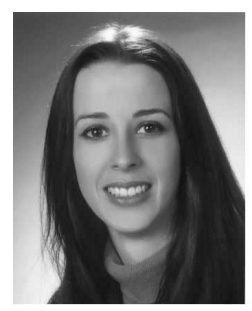

Sarah Follmann was born in 1978 in Germany. She received a German Diplom in Electrical Power Engineering from the University of Applied Sciences Trier in 2002 and an MSc in Sustainable Energy Systems from the University of Manchester in 2006. Her master dissertation formed part of the research into dielectric behaviour of silicone gel as used in high voltage power electronic modules. Currently, she is a Project Engineer with Siemens Transmission and Distribution Ltd.

Kim Evans was born in UK in 1973. She received a BSc from Manchester University in 1984 in material science. She is currently working as a Development engineer for Dynex semiconductors ltd.

David Newcombe was.. 